Stream: Culture/Politics/Technology, 5(1): 29-36

http://journals.sfu.ca/cpt/index.php/stream/index

\title{
Environmental infomediaries in the Risk Society: The behavioral impact of online environmental information and communication strategies
}

\section{Matt Godfrey}

Department of Communication and Culture, University of Calgary

\begin{abstract}
The expansion of the online marketplace changed the way many people consume products and information by allowing consumers to conduct increasing amounts of pre-purchase research. Many organizations developed online tools to help consumers efficiently find and use environmental information to make more sustainable purchase decisions. In this paper I explore the impact and efficacy of these online environmental infomediaries through an analysis of their history, methods, and impact. Using a framework developed from Ulrich Beck's theory of the Risk Society and Bettman's theory of contingent decision making, I conducted a preliminary case study of GoodGuide.com, a well-known online environmental infomediary. Based on this framework, I found that effective online environmental infomediaries (1) target educated, internet-savvy, leisure- and trend-oriented consumers; (2) focus on high-risk, non-convenience purchases; (3) provide visually appealing and interactive tools; (4) ensure information tools are easy to use and understand; (5) employ a clear and transparent methodology; and (6) satisfy consumers' expectations of their efficacy. GoodGuide.com excelled at several of these criteria, but its opaque methodology and failure to meet most consumers' expectations may threaten its long-term viability.
\end{abstract}

\section{Keywords}

environmental infomediary, risk society, online environmental information

\section{Introduction: The Internet and the Infomediary}

Consumers rely increasingly on information available from diverse online sources throughout the process of consumption. This new appetite for information may provide an avenue for environmental information to promote more environmentally sustainable choices. However, the seemingly endless supply of information provided by the Internet may also cause environmental "information overload" (Jacoby, 1984). Given the importance of addressing environmental issues today and the growing influence of the Internet and mobile technologies, this paper attempts to understand the internet's effect on environmental information intermediaries and their impact, in turn, on communicating and encouraging environmentally sustainable consumer behavior.

Broadly defined, information intermediaries, or infomediaries, include any "human or nonhuman party designed to assist consumers in information processing" (Lee \& Cho, 2005). While human infomediaries such as lawyers or librarians remain important in the electronic age, the nearly exponential growth of information available on the Internet makes online infomediaries increasingly vital.

During the late 1990s dot com boom, the number of products available for purchase online grew beyond customer's sorting ability. Increasing Internet shopping traffic also meant that corporations had access to more customer information than they could use. They often sold it, and customers began to grow tired of companies trading their private information. Into the middle of this clutter came the "infomediary," a third party information dealer who could mediate between customers and corporations and provide both groups with the information and value they wanted (Hagel \& Singer, 1999). This early business model led to the coining of "infomediary" as a term, but its use spread much wider in the following years. Online retail stores such as Amazon utilize the 
infomediary model by providing user friendly, all-in-one tools for customers to "get information, compare information and... undertake transactions on the web" (Sharma \& Sheth, 2004).

Meanwhile, many organizations attempt to assist people in receiving and processing environmental information. Given this paper's focus on online environmental infomediaries' capability to change consumer behavior, I will limit my analysis to online environmental infomediaries (OEIs) designed specifically to influence purchase decisions. Consumer purchases represent a significant source of environmentally unsustainable production and consumption, as well as a potential avenue to change these practices. To explore the question of OEI effectiveness, this paper will discuss the history of environmentalism and OEIs, develop a theoretical framework to help explain their efficacy, and conduct a short case study of GoodGuide, a well-known OEI.

\section{The Environmental Movement and Its Infomediaries}

In the United States ${ }^{1}$, the first major opposition to human domination and exploitation of nature appeared during the transcendentalist movement of the early and mid-nineteenth century. Transcendentalists like Henry David Thoreau argued for the preservation of nature for moral, religious, or sentimental reasons that stemmed from close personal connections with the wilderness (Kline, 2007).

The second environmental wave hit the United States in the late nineteenth century. John Muir, founder of the Sierra Club, led a revival of the transcendentalist notion "that a divine spirit flowed through the whole of nature" (ibid, p. 48). Muir's public promotion of environmental ideals succeeded in many of its goals, including the creation of Yosemite National Park in California.

Then, at the beginning of the twentieth century, President Theodore Roosevelt and Gifford Pinchot, the United States' first forestry management scientist, pushed for the managed exploitation of nature to ensure future generations could have access to environmental resources (Kline, 2007). Scientific information rather than sentimental ideals played the most important role in this movement, although the dissemination of this data focused more on the realm of public policy rather than public opinion. A struggle between science and sentiment continued until about two decades later when Aldo Leopold, a conservationist and professor trained at the Yale Forestry School, advocated for a method of environmentalism based on science instead of religion or romanticism (ibid). Organizations such as the Sierra Club began to adopt Leopold's view, believing that in order to gain public and government support, the environmental movement needed to act as an intermediary of scientific environmental information.

Fifty years later, a marine biologist named Rachel Carson gained renewed support for the environmental movement, which had dropped from the public eye through two world wars and the Great Depression. Carson, through her books The Sea Around Us (1951) and Silent Spring (1962), demonstrated an uncanny ability to convey the technical and complex problems of environmental issues. As effective environmental infomediaries, her books shocked many Americans into action and birthed a new environmental movement (Kline, 2007). This new environmental information changed the minds of many members of the public -- and the environmental policies in the United States.

Advances in mass communication allowed for a growing number of new environmental infomediaries to gain attention from mass audiences. Following the advent of the internet, environmental organizations took advantage of online media in the same way that they utilized print and television in the past. The Internet, however, boasted a much higher capacity for information. Online data became increasingly difficult to sort through due to its increasing volume, which made OEI tools essential for promoting behavior change and breaking through "data smog" (Shenk, 1997). In contrast to the pre-internet age, when the limitations of published books, articles, and news kept the scope and reach of environmental information within relatively narrow bounds,

Stream: Culture/Politics/Technology, Volume 5, Number 1 
the internet allowed the expedited publication and indefinite storage of all available environmental data. OEIs became critically important to make this information useful to everyday consumers.

OEIs utilized stories about important environmental issues, databases of corporate environmental policies, eco-labeling schemes, and product rating systems, among other tools, to mediate existing and new information. Greenpeace, for instance, developed an infomediary tool called the "Guide to Greener Electronics" to collect and analyze environmental information on electronics in order to produce company and product ratings for mobile phones and computers (Greenpeace, 2012). These types of OEIs assume that if significant numbers of consumers use their information to make purchase decisions, they can effectively encourage environmentally sustainable consumption and force corporations to respond to this new demand.

The theory of risk society outlined by Beck (1992) and Giddens (1990) provides a deeper understanding of the social context within which environmentally-impactful consumer decisions are made. Industrial modernization created an infinite supply of invisible and unavoidable environmental and social hazards - these risks are inextricably bound to industrial development (Beck, 1992; Giddens, 1990). Under such circumstances, science will ultimately fail to prevent environmental damage, as even the production of risk aversion technologies result in new unforeseen risks (Beck, 1990). However, following Aldo Leopold's example, many environmental infomediary organizations also use techno-scientific rationality to push the cause of sustainability. They develop and communicate scientific risk assessments in order to awaken members of the public who, in the eyes of environmentally-conscious experts, downplay or ignore the risks that their everyday actions create (Marx et al., 2007).

Growing concern about environmental risk within many scientific and political communities has led to what Szerzynski, Lash, and Wynne (1996) called "an overproduction of expertise on green issues" (p. 1). Many environmental risk experts work to develop "instruments of prediction and control" that hope to manage environmental issues by increasing social and natural scientific research about them (Szerzynski, Lash \& Wynne, 1996, p. 4). This top-down approach eliminates the consideration of more enduring and participatory forms of change, and further strengthens the hold of the dominant scientific paradigm (Szerzynski, Lash \& Wynne, 1996). Effective OEIs, then, must provide open and transparent information in order to facilitate greater participation and longterm behavior change. Extensive studies on online medical infomediaries have found empirical evidence supporting this call. Online medical infomediaries could only attain long-term success if they employed transparent information-filtering methodologies and met consumers' needs and expectations (Jadad \& Gagliardi, 1998; Kim et al., 1998). By comparison, opaque, top-down infomediaries generally failed within two or three years (Jadad \& Gagliardi, 2002).

\section{Theoretical Framework}

Gaining an appropriate perspective on OEIs in an internet society requires a theoretical framework that accounts for micro-level environmental decisions, as well as macro-level social and cultural forces that impact the environment. The complex and often unpredictable nature of choice in real life makes a perfectly "economical" perspective of decision-making impossible (Bettman, 1991). Simon (1955) first challenged the notion of purely rational decision-making by illustrating that human beings could only retain, utilize, and process a finite amount of information. In this theory of "bounded rationality," Simon explained that people make rational decisions only as far as limitations such as information availability, memory capacity, and number of alternatives allow.

Bettman et al. (1991) built the theory of contingent decision-making upon Simon's arguments in order to provide a model that illustrated the ways consumers decide how to decide. Bettman et al argued that three main factors influence how consumers' decide to solve a problem: the nature of the problem, the characteristics of the person, and the social context within which the person operates.

Stream: Culture/Politics/Technology, Volume 5, Number 1 
Elements that influence the characteristics of the decision problem include the number of available alternatives, the influence of time pressure, and the ability to differentiate between the values of alternatives. With fewer available alternatives a person processes information to make a conscious choice more often, and vice-versa. Increased time pressure generally leads consumers to take decision making shortcuts rather than to process and compare information. Additionally, the more difficult it becomes to identify and differentiate the values and attributes of alternatives, the more difficult the choice becomes (Bettman, 1991).

The decision maker's personal characteristics depend largely on his or her ability and prior knowledge of and familiarity with possible ways of decision making (Bettman, 1991). These personal characteristics include individual preferences as well as social contexts, which depend on a person's accountability and group memberships. The people and groups to which consumers feel that they must justify their actions influence the way they choose to process information and make decisions (ibid). In an environmental context, consumers will employ information searches to inform a sustainable purchase when they believe that doing so aligns with the goals and norms of their social circles.

Researchers have already utilized Bettman's theory of contingent decision-making to describe online purchase and information search behaviors generally. For example, Moon (2004) found that consumers' likelihood of using the Internet to conduct pre-purchase research also depended on personal, problematic, and contextual characteristics. Progressive, Internet-savvy consumers who value leisure time and new trends chose to utilize the Internet for product-related information searches much more frequently than consumers with less internet experience and different values or goals. Products that already required some level of pre-purchase research-relatively high-risk purchases made infrequently enough to encourage shopping around-also led consumers to conduct more online information searches. Finally, the quality, design, and user-friendliness of online information greatly increased consumers' likelihood of using Internet-based infomediaries in current and future searches.

In summary, contingent decision making provides a fairly clear picture of the ideal person, problem, and social context for an OEI to influence. Operating in an Internet-mediated environment, an effective OEI must target educated, Internet-savvy, leisure-oriented people who are interested in new trends and feel socially-compelled to make educated, "eco-friendly" decisions. An effective OEI must also focus on informing "shopping" product decisions (i.e., riskier, non-convenience purchases) with quality information, and a well-designed, easy-to-use format. Moreover, effective OEIs must not only target the right person and the right problem, they must also provide open and transparent information in order to facilitate greater participation and long-term behavior change.

In this study, I examine one well-established online infomediary, GoodGuide.com, under the lens outlined above. GoodGuide.com's content, design, and user ratings allowed for a simple content and efficacy assessment of the site as a case study of the online environmental infomediary. The analysis represents an initial view of an OEI's methods, impact, and potential efficacy. While a more in-depth analysis is required, the findings presented are important in that they form a basis and justification for such a research project focused on GoodGuide.com and other OEIs.

\section{Case Study: Goodguide.com}

GoodGuide was founded in 2007 by Dara O'Rourke, a professor at the University of California, Berkeley and a global supply chain expert (GoodGuide, 2012a). O'Rourke became determined to develop an online infomediary tool for environmentally responsible consumption after learning that many of the health and hygiene products he bought for his daughter contained dangerous chemicals and carcinogens (Miller, 2009). GoodGuide employs a team of scientists who collect and analyze environmental and social data for thousands of products and companies. GoodGuide then uses these data to generate a score for each of the products and companies, which consumers can

Stream: Culture/Politics/Technology, Volume 5, Number 1 
search and access using the Internet or GoodGuide's mobile app. GoodGuide makes profit by selling advertising, as well as customized "business intelligence reports" that compare the social and environmental performance of a company with its competitors (GoodGuide, 2013). Although GoodGuide was recently purchased by Underwriters Laboratories, one of the world's largest and most influential quality assurance companies (Underwriters Laboratories, 2012), it continues to operate independently as a subsidiary (GoodGuide, 2012b).

Operating in an Internet-mediated environment changes the way that environmental infomediaries need to communicate to consumers in several ways. Based on conclusions drawn from the literature reviewed above, I developed a set of criteria from which to judge an OEI. Effective OEIs should (1) target educated, Internet-savvy, leisure-oriented, and trend-oriented consumers; (2) focus on high-risk, non-convenience purchases; (3) provide visually appealing and interactive tools; (4) ensure information tools are easy to use and understand; (5) employ a clear and transparent methodology; and (6) satisfy consumers' expectations of its efficacy.

Comparing the six criteria outlined above with GoodGuide's current infomediary practices, I rated its performance as an OEI. These ratings represent an initial analysis only. As explained in further detail in the conclusion, a deeper, more structured analysis must be conducted in order to extend the usefulness of these results. However, these findings provide important insights that should form the foundation for future research endeavors.

\section{Target Customer}

GoodGuide's usage appears to have grown fairly steadily (Miller, 2009), and reports have stated that GoodGuide is "one of the biggest successes among green apps." (Graham, 2011) GoodGuide's online and mobile success, at least in terms of total unique visitors and app downloads, indicates that the company targeted Internet-savvy environmentalists well.

\section{Product focus}

A complete analysis of GoodGuide's database of tens of thousands of products is beyond the scope of this paper. However, a review of the categories featured and products rated shows that GoodGuide hopes for a very broad reach. GoodGuide adds products to its lists based on market share and consumer demand, aiming to "cover the products that constitute $80 \%$ of current sales in a category." (GoodGuide, 2012a) GoodGuide does cover many "non-convenience" products such as televisions, vehicles, and computers. However, it also includes thousands of everyday, routine purchase like granola bars, diapers, and air fresheners. Although consumers may not use GoodGuide as often for routine products as for big-ticket items, a broad scope doesn't necessarily hurt its overall chances of winning and retaining new users.

\section{Visually-appealing, interactive tools}

GoodGuide's design team delivers a continually-improving web and mobile interface. Recognition for its design has come from high-profile media (Sacks, 2012), and the mobile app's innovative barcode scanner function makes GoodGuide very interactive. GoodGuide also allows users to customize ratings based on issues and criteria that are important to them. Its newest mobile apps also let users connect their GoodGuide and social media accounts.

\section{Understandable, easy-to-use information}


In line with the above, GoodGuide prides itself on ease-of-use, straightforwardness, and simplicity. The most recent mobile app version contains several updates, which include changes aimed at "making things look a bit more, well, slick" and "work a little more intuitively" (iTunes, 2012). Simple zero-to-ten rating scales allow users to quickly digest and utilize the results of environmental data analysis done by GoodGuide's scientists.

\section{Clear, transparent methodology}

Although GoodGuide claims to be "committed to transparency" it cannot reveal many of its raw data sources due to reliance on corporate license agreements and complicated (and thus difficult to share and publish) research and analysis. It also outsources some of its scoring to third parties, who cannot disclose their own proprietary methods (GoodGuide, 2012b, 2012c). User satisfaction-as explained below-indicates that many consumers find GoodGuide's lack of transparency somewhat frustrating. Its opaque methodology and data sources might also hurt GoodGuide's credibility with the companies it rates.

\section{Consumer satisfaction}

iTunes user ratings of GoodGuide's mobile app provide the best source for user satisfaction data on the use of this OEI. The app's over 1,100 user reviews represent approximately $1.5 \%$ of GoodGuide's total iPhone app downloads, assuming marginal growth in downloads over the most recent statistic of 600,000 downloads (Graham, 2011). User ratings placed the app at a less-thanideal 2.5 stars out of five. GoodGuide's mediocre satisfaction ratings might present its most challenging obstacle, especially given high expectations of corporate engagement and transparency in the ultra-interactive age of Web 2.0.

\section{Discussion and Conclusion}

GoodGuide excelled at several of the criteria identified by the framework I developed from the literature. Its Internet-savvy, eco-aware target customers and its interactive, easy-to-use information tools point toward potential success in an online setting. However, its opaque methodology and failure to meet many consumers' expectations may threaten its long-term viability.

These results call for a more detailed and structured analysis of GoodGuide's methods, ratings, and efficacy. Such a research project necessitates a multi-method approach that combines textual analysis of GoodGuide's iTunes reviews and its own product ratings and descriptions, as well as a thorough analysis of its research methodology and overall mission through the lens of Beck's (1991) and Giddens' (1990) open, participatory concept of new modernity.

OEIs represent a potentially powerful tool for influencing environmentally sustainable consumer choices. Consumer demand for sustainable products might have the potential to shift production practices and increase producer transparency toward more action and concern for environmental issues. By actively engaging consumers in this process of increased accountability, OEIs will help ensure that behavior changes achieved through OEIs can be sustained over the long term. Perhaps open-source reviews and ratings such as those facilitated by Yelp and Google+ provide some insight into how OEIs might involve proactive users. While an open approach to ratings may negatively affect the scientific validity of GoodGuide's environmental information, it may also positively affect the perceived trustworthiness and usefulness of this same information.

Throughout recent history, environmental infomediaries followed consumers' patterns of media consumption from poetry, newsprint, and books to Internet connectivity, social media, and 
interactive mobile technology. OEIs must now embrace the high demands for engagement, transparency, and efficacy that Web 2.0 consumers call for in order to successfully encourage consumers to utilize their information tools to make environmentally sustainable purchase decisions.

\section{Notes}

1. Although written in Canada by a Canadian, this paper uses U.S. environmental history as a proxy due to the relative abundance of American research, as well as Canada's close ties with and similarities to many American environmental attitudes and policies.

\section{References}

Beck, U. (1992). Risk society: Towards a new modernity. New York: Sage.

Carson, R. (1951). The sea around us. New York: Oxford University Press.

Carson, R. (1962). Silent spring. Boston: Houghton Mifflin.

Giddens, A. (1990). The consequences of modernity. Stanford, California: Stanford University Press. Bettman, J.R., Johnson, E.J., \& Payne, J.W. (1991). Consumer decision making. In T.S. Robertson \& H.H. Kassarjian (Eds.), Handbook of Consumer Behavior (50-84). Englewood Cliffs, New Jersey: Prentice-Hall.

GoodGuide. (2012a). Frequently asked questions. Retrieved December 10, 2012 from http://www.GoodGuide/about/faq

GoodGuide. (2012b). GoodGuide's data. Retrieved December 10, 2012 from http://www.GoodGuide/about/data

GoodGuide. (2012c). Methodology. Retrieved December 10, 2012 from http://www.GoodGuide/about/methodologies

GoodGuide. (2013). About us. Retrieved November 13, 2013 from http://www.goodguide.com/about

Graham, J. (May 13, 2011). GoodGuide app helps navigate green products. USA Today. Retrieved from: http://usatoday30.usatoday.com/tech/products/2011-05-12-GoodGuide-app_n.htm

Greenpeace International. (2012). Guide to greener electronics. Retrieved from http://www.greenpeace.org/international/en/campaigns/toxics/electronics/

iTunes. (2012) GoodGuide [App available on the Apple iTunes store]. Retrieved December 10, 2012 from https://itunes.apple.com/ca/app/goodguide/id294447660?mt=8

Jacoby, J. (1984). Perspectives on information overload. The Journal of Consumer Research, 10(4), 432-435.

Jadad A. \& Gagliardi A. (1998). Rating health information on the internet: Navigating to knowledge or to Babel? Journal of the American Medical Association, 279(8), 611-614.

Gagliardi, A., \& Jadad, A. R. (2002). Examination of instruments used to rate quality of health information on the internet: Chronicle of a voyage with an unclear destination. British Medical Journal, 324(7337), 569-573.

Kim, P., Eng, T. R., Deering, M. J., \& Maxfield, A. (1999). Published criteria for evaluating health related web sites: Review. British Medical Journal, 318(7184), 647-649.

Kline, B. (2007). First along the river: A brief history of the U.S. environmental movement. Lanham, Maryland: Rowman \& Littlefield.

Lee, J., \& Cho, J. (2005). Consumers' use of information intermediaries and the impact on their information search behavior in the financial market. Journal of Consumer Affairs, 39(1), 95-120.

Marx, S. M., Weber, E. U., Orlove, B. S., Leiserowitz, A., Krantz, D. H., Roncoli, C., \& Phillips, J. (2007). Communication and mental processes: Experiential and analytic processing of uncertain climate information. Global Environmental Change, 17(1), 47-58. 
Miller, C. (June 14, 2009). On web and iPhone, a tool to aid careful shopping. The New York Times. Retrieved from http://www.nytimes.com/2009/06/15/technology/Internet/15guide.html?_r=0

Moon, B. J. (2004). Consumer adoption of the internet as an information search and product purchase channel: Some research hypotheses. International Journal of Internet Marketing and Advertising, 1(1), 104-118.

Sacks, D. (July 12, 2012). Most innovative companies 2010. Fast Company. Retrieved December 10, 2012 from http://www.fastcompany.com/mic/2010/profile/good-guide

Shenk, David. (1997). Data Smog. New York: Harper Collins.

Simon, H. A. (1955). A behavioral model of rational choice. The Quarterly Journal of Economics, 69(1), 99-118.

Szerzynski, B., Lash, S., \& Wynne, B. (1996). Introduction: Ecology, realism, and the social sciences. In S. Lash, B. Szerzynski, \& B. Wynne (eds.), Risk, environment \& modernity (pp. 1-26). London: Sage. 